\title{
Monitoring of minimal residual disease in acute leukemia by multiparametric flow cytometry
}

\author{
Minireview
}

J. KUSENDA*, M. FAJTOVA, A. KOVARIKOVA

Cancer Research Institute, Slovak Academy of Sciences, Vlarska 7, 83391 Bratislava, Slovakia

*Correspondence: exonkuda@savba.sk

Received June 6, 2013 / Accepted June 20, 2013

\begin{abstract}
In this review, we discuss methodological principles and clinical applications of minimal residual disease (MRD) assays based on multiparameter flow cytometry (MFC). The introduction of methods for MRD detection has revolutionized monitoring of treatment response in acute leukemia. Great progress has been made in the development of wide array of flow cytometric techniques for rare event detection. This advance was accompanied by increasingly greater understanding of the immunophenotypic features of leukemic and normal lymphoid cells, and of the antigenic differences that make MRD studies possible. Immunologic testing of MRD relies on "leukemia-associated" immunophenotypes which can be identified by MFC in the most of acute leukemia cases. The recent technical innovations in routine MFC ( 3 lasers and $\geq 8$ colors) and the new developments in software for data analysis make this technology the most attractive for MRD diagnostics. The importance of MFC methodology will be further strengthened by the ongoing international standardization efforts. Results of MRD testing provide unique and clinically important information. The systematic application of immunologic techniques to study MRD in clinical samples has demonstrated the prognostic significance of MRD in patients, leading to the use of MRD to regulate treatment intensity in many contemporary protocols. The identification of new markers of MRD should increase the sensitivity of MRD testing by MFC and is required to widen the applicability of MRD studies.
\end{abstract}

Key words: minimal residual disease, acute leukemia, multiparameter flow cytometry, prognostic factors, remission

\section{Minimal residual disease (MRD)}

In patients with acute leukemia conventional pretherapeutic risk criteria, including age, elevated white blood cell count at diagnosis, adverse immunophenotypic features, and cytogenetic as well as molecular aberrations provide the basis for upfront risk stratification in current treatment protocols. Response of leukemia to treatment depends on a combination of multiple factors, such as properties of the leukemic cells (e.g. proliferative capacity, expression of regulators of apoptosis, drugs resistance, influence treatment response and other escape mechanisms), host factors (e.g. concomitant diseases, treatment compliance, host pharmacodynamics and pharmacogenetics, the effect of the microenvironment), and treatment given to eradicate the disease. Many of intrinsic leukemia cells and host factors have already been elucidated with immunologic and molecular methods and are ongoing translated into providing prognostic information [1].

Survivals of acute leukemia patients with relapse are still the main clinical problem. The source of these relapses is the persistence of minimal residual disease (MRD) that is defined as disease that is undetectable by standard diagnostic techniques (morphology). In patients with leukemia, MRD signifies leukemic cells undetectable by morphologic examination of bone marrow smears. The introduction of methods for MRD detection has revolutionized monitoring of treatment response in acute leukemia. Currently available methods for detection of MRD are at least 100 times more sensitive than morphologic analysis. Because they rely on specific leukemia markers rather than on subjective recognition of morphologic 
patterns, MRD assays are also much more objective. Acute lymphoblastic leukemia (ALL) has been at the forefront of the development of MRD methods. Progress in introducing MRD testing into the clinic was initially widely supported as some investigators were concerned that the distribution of leukemic cells during treatment might be too heterogeneous for MRD testing to be accurate. In fact, the strong correlation between levels of MRD and relapse risk suggests that, at least at the early stages of therapy, ALL distribution is quite homogeneous [2]. Other investigators insisted that progress in ALL prognostication could only occur by focusing on the genetics of leukemic cells. However, MRD measurements should be inherently more informative than any leukemic cell features as they reflect the effect of several other variables that influence treatment response and outcome [3]. Measurements of the response to the early phases of therapy using MRD-detection techniques provide a good indication of the susceptibility of leukemic cells to chemotherapy in each patient and represent the most accurate prognostic indicator that is currently available. MRD-detection methods have many potential applications in the clinical management of patients with acute leukemia (childhood and adult ALL and acute myeloblastic leukemia) including recognition of leukemia relapse before it is clinically evident and determination of the leukemia burden before hematopoietic stem cell transplantation. A more recent application includes the use MRD as a parameter for measuring the efficacy of a new remission induction regimen in relation to that of a previous protocol; this can detect early whether the new regimen is significantly inferior to the previous one, thus prompting changes and reducing the number of patients exposed to suboptimal therapy $[1,3]$. Consequently, an increasing number of treatment protocols use MRD as a tool for treatment stratification. MRD levels during remission induction therapy provide important prognostic information.

Two main approaches have been demonstrated to provide clinically meaningful MRD results: 1) polymerase chain reaction (PCR) analysis of fusion transcripts of leukemia-specific chromosomal translocations, and of clone-specific chain joining regions of immunoglobulin (Ig) and T-cell receptor (TCR) rearrangements 2) immunophenotyping using flow cytometry and multiple markers to identify leukemia-specific immunophenotypes [4]. One limitation of current studies of MRD based on PCR amplification of Ig/TCR genes is that specific PCR primers need to be developed for each patient and thus, PCR assay conditions need to be individually optimized. The process is laborious, expensive, and time consuming. Sensitivity of PCR methods can be determined exactly and currently tends to be $0.5-1.0 \mathrm{log}$ higher than flow cytometric MRD assessment. However, a main disadvantage of using gene rearrangements as MRD targets in acute leukemia is occurrence of continuing rearrangements during the disease course, potentially leading to false-negative PCR results. Also, false positivity cannot be completely excluded, as massive regeneration of normal lymphoid progenitors might lead to low levels of nonspecific amplification [5]. Current strategy is apply preferentially flow cytometry to monitor MRD during remission induction therapy and to develop a PCR assay for antigen-receptor genes (or fusion transcripts) only if a suitable immunophenotype cannot be identified. In conclusion, each of these techniques has its own strengths and limitations [1,3]. A reliable technique to detect MRD should have the following prerequisites:

- sensitivity of at least 1:10,000 (one malignant cell within 10,000 normal cells), although the target value of sensitivity depends on the clinical question to be addressed by the MRD assessment

- specificity, to discriminate between malignant and normal cells (to prevent false-positive results)

- be quantifiable within a large dynamic range

- stability over-time of leukemia-specific markers (to prevent false-negative results), particularly in long-term studies

- reproducibility between laboratories (essential for multicentre trials)

- standardization and quality control checks

- rapid availability of results (in time for clinical usefulness) $[3,6]$

The productivity of MRD as a measurement of drug response in vivo opened new perspectives for its use in clinical decision [6]. In this review, we discuss methodological principles and clinical applications of MRD assays based only on flow cytometry.

\section{Multiparameter flow cytometry (MFC)}

To detect MRD it is necessary to identify distinguishing features of the leukemic cells and then develop methods that can reliably detect them with high sensitivity and accuracy. One of the distinguishing features of leukemic cells in most cases of ALL and acute myeloblastic leukemia is the expression of cell markers in such combinations that are not found during normal hematopoietic differentiation. These aberrant cell profiles can be detected by multiparameter flow cytometry (MFC) $[1,3]$. MRD measurement by MFC is based on the detection of these leukemia-associated immunophenotypes (LAIP) that can be used to distinguish them from normal hematopoietic cells. The LAIPs usually describe a subpopulation of cells of a given lineage at a particular differentiation stage with aberrant molecular expression patterns, asynchrony, and/or profound overexpression or underexpression of some molecules. The sensitivity of this approach depends primarily on the degree of dissimilarity between the aberrant immunophenotypes of the leukemic cells and immunophenotypes of normal cells. The number of cells available for study also plays a role in determining the sensitivity of the assay. Leukemic lymphoblasts differ from physiological lymphoid precursors in qualitative (for example, by presence of myeloid markers) and quantitative antigen expression patterns.

As for molecular methods, most published MFC data have been based on bone marrow analysis (with EDTA or heparin as preservative). Both gradient separation and erythrocyte lysis 
are used as preparation methods. A minimum of $3(-5) \times 10^{6}$ nucleated cells should be available. Shipment time is an important issue when analyzing viable cells and should optimally not exceed $24 \mathrm{~h}$ [7]. Studies of MRD are usually performed in bone marrow. However in patients with T-lineage ALL when MRD levels in peripheral blood are similar to those in bone marrow, indicating that in those patients MRD testing can be performed in blood. The use of flow cytometry technique dates back more than 25 years, starting with 2 - and 3-color approaches. The implementation of more than 4-color techniques increased sensitivity or specificity of this method, and allowed for its application simultaneous determination of extensive phenotypic patterns at the single-cell level. Furthermore, the recent technical innovations in routine multicolor MFC and the new developments in software for data analysis make this technology increasingly attractive for MRD diagnostics. The current application of MRD diagnostics has become possible by intensive networking processes and open collaboration between clinical and diagnostic research groups throughout Europe. In addition to national networks, two international consortiums, the I-BFM-ALL-FLOW-MRD Network and the EuroFlow Consortium were established in Europe to optimize and standardize FCM-based MRD quantification [7]. The EuroFlow Consortium works on full standardization on instrument setups, sample preparation, immunostaining procedures, fluorochromes and 8-color antibody panels, as well as bioinformatics-assisted expert independent automated analysis of the acquired data [8]. Standardization of methodologies and definitions of common MRD terms become increasingly important, not only to ensure comparability of MRD data between different MRD laboratories but to provide a sound basis for the comparison of MRD results between different treatment protocols. Owing to the collaborative attitude of all involved teams, the current key position of MRD diagnostics has been reached. Continuation of such collaboration, high-level standardization and regular quality control rounds remain critically important for further improvements in MRD diagnostics [7].

The major advantage of MFC is its rapidity, which allows results reporting within one day. This is particularly useful when MRD results are required quickly to guide therapy. In addition, MFC allows the simultaneous assessment of cell qualities that are required for emerging targeted therapies in acute leukemia [9]. A potential pitfall of the method results from similarities between leukemic lymphoblasts and nonmalignant lymphoid precursors in various phases of regeneration during and after chemotherapy that may lead to false positivity [10]. Hence, initial phenotypes serve only as orientation and not for planning strict gating strategies in follow-up. Nowadays, expert knowledge of typical time-point-related nonmalignant background and experience with patterns of phenotypic shifts of leukemic cells is essential to distinguish MRD properly. As MFC and PCR do not lead to completely comparable results; MFC cannot simply substitute current PCR-based MRD risk stratification at the same time points
[11]. Several studies on direct comparison between MFC and molecular MRD data have been performed [12,13]. Generally, when 3-4-color MFC MRD data are qualitatively compared with PCR-based MRD data, the reported concordance varies from $70 \%$ to over $95 \%$, depending on the time point and the related MRD level. A true quantitative comparison using both approaches was performed in samples in which both methods detected MRD levels above $0.01 \%$ a significant relation was observed [14]. The introduction of 3-color MFC (in the early nineties) and 4-color MFC (in the late nineties) significantly improved the applicability and sensitivity for MRD analysis. It can be expected that the introduction of 6-8-color flow cytometers further improves the applicability and sensitivity of MRD detection in acute leukemia. The use of 6-8-color MFC (including new markers and new marker combinations) not only increases the multicolor capabilities, but also allows addition of new informative markers as well as a more optimized composition of the antibody panels and clearly improves the specificity of the immunopenotypic analysis. Furthermore, introduction of nine or more color-immunostainings allows combinations of multiple markers in a single tube, thereby facilitating the acquisition of large numbers of cells, which is essential to increase the sensitivity of MFC. To reach MFC sensitivities of at least 1:100,000 (comparable to PCR) acquisition of at least two million cells is required. These are the aims of the currently ongoing EuroFlow Consortium $[8,15]$.

\section{MRD in acute lymphoblastic childhood and adult leukemia (ALL)}

The clinical importance of MRD has been demonstrated by numerous studies using either MFC or PCR and involving thousands of newly diagnosed childhood and adult patients with ALL, patients with relapse ALL, and those undergoing hematopoietic stem cell transplantation. Results are in remarkable agreement on the association between MRD persistence and risk of subsequent relapse, regardless of the MRD detection method is used [16]. More recent data indicate that MRD can also be informative in specific subgroups of ALL patients, such as infants or those with T-lineage ALL. Hence, MRD is now being used in clinical trials to inform on about treatment decisions and guide patients' clinical management [17]. The technical aspects of MFC and PCR tests, as well as their specific strengths and limitations have been reviewed elsewhere $[2,3,7]$. LAIP can be identified in virtually all patients at diagnosis; flow cytometry targeting these immunophenotypes affords a sensitivity of MRD detection of $0.01 \%$. Results of flow cytometry are usually in agreement with those of PCR if the level MRD is at or above the $0.01 \%$ [12]. Coustan-Smith et al. [18] compared genome-wide gene expression of lymphoblasts from 270 patients with newly diagnosed childhood ALL to that of sorted normal CD19+CD10+ B cell progenitors from four healthy donors. They then selected 30 genes differentially expressed by more as threefold in at least $25 \%$ of cases of ALL 
and tested their expression by MFC in 200 B-lineage ALL and 61 non-leukemic bone marrow samples. They included recovering bone marrow samples, which pose a particular challenge in MRD studies because of their high proportion of normal immature lymphoid cells. Of 30 markers, 22 were found to be differentially expressed in up to $81 \%$ of ALL cases. When the new markers were applied to study MRD in clinical samples, they yielded results that correlated well with those obtained by standard MFC and PCR. Sequential studies during treatment and diagnosis-relapse comparisons documented their stability. The addition of the new markers to established panels allowed the identification of unique leukemia profiles in all patients [18].

Correlative studies from different groups have demonstrated that MRD testing during and at the end of remission induction therapy, and in the early phases of post-remission treatment provide strong prognostic information in childhood ALL [19, 20,21,22]. Borowitz et al. measured MRD in bone marrow collected on day 29 of therapy from 2086 patients with B-ALL who were enrolled in series treatment protocols and found that $0.01 \%$ or more MRD estimated by MFC was significantly associated with a worse outcome [19]. Basso et al. [20] studied bone marrow samples from 830 patients by MFC. MFC was the most important prognostic factor among those available by day 15, with two-fold and five-fold increase in the risk of relapse compared with patients with less than $0.1 \%$. High levels of MFC MRD retained an independent ability to detect a significantly higher risk of relapse [20]. In a study of 3184 B-ALL patients enrolled in the AIEOP-BFM ALL 2000 protocol a large cohort of patients demonstrated the prognostic significance of MRD in B-ALL [21]. Stow et al [22] examined the clinical significance of levels below the usual threshold value for MRD positivity $(0.01 \%)$ in 455 children with B-ALL and confirmed the adverse prognostic impact of MRD. Low levels of MRD $(0.001 \%<0.01 \%)$ at the end of remission induction therapy have prognostic significance in B-ALL patients and suggesting that patients with this finding should be monitored closely for adverse events. Van der Velden et al. [23] studied MRD in 99 infants with ALL and demonstrated the prognostic significance of MRD; all patients classified as high-risk because the value of MRD was more than $0.01 \%$ at the end of induction and/or consolidation. Schrappe et al. [24] studied 464 patients with T-ALL and found that $\mathrm{MRD}<0.01 \%$ at the end of induction was the most favorable prognostic factor, with patients converting to MRD negativity at the end of consolidation also having a favorable outcome, while patients with $\mathrm{MRD} \geq 0.1 \%$ at this time point had a high relapse hazard.

Several studies have also demonstrated the clinical impact of MRD in adult patients with ALL. The German Multicenter Study Group for Adult ALL studied 196 patients younger than 65 years with ALL and achievement of complete remission after the first phase of induction therapy. Patients with $\mathrm{MRD}<0.01 \%$ had a 3-year relapse rate of $0 \%$; with $M R D \geq 0.01 \%$ until week 16 had a relapse rate of $94 \%$ [25]. MRD was studied at the end of consolidation in patients enrolled in the Northern Italy leukemia Group-ALL. Five-year overall disease-free survival was $14 \%$ for the 54 patients with $\mathrm{MRD} \geq 0.01 \%$ and $72 \%$ for 58 patients with $\mathrm{MRD}<0.01 \%$ [26]. Patel el al. [27] corroborated the prognostic significance of MRD in patients with non Tlineage ALL and found that the relative risk of relapse was nine times higher in patients who were MRD-positive after Induction 2 than in those who were MRD-negative. Finally, MRD was measured on bone marrow samples from high-risk children and adult ALL patients in a French multicenter prospective study [28]. At diagnosis, all 238 patients had at least one suitable MRD marker with $0.01 \%$ sensitivity. It should be noted that the proportion of MRD-positive samples at any given time point during the course of treatment for patients with ALL is highly dependent on the preceding therapy and hence varies widely among different studies. Consequently, the interpretation of the clinical siginificance of MRD results needs to be considered in the context of each treatment regiment $[3,17]$.

\section{MRD in acute myeloblastic leukemia (AML)}

Acute myeloblastic leukemia (AML) is a heterogeneous disease of early myeloid cell differentiation. In a majority of individuals, the causative factor for development of leukemia is unknown. Patients with AML show a heterogeneous response to therapy. The current standard of care involves an intensive induction chemotherapy followed by post-remission consolidation treatment including additional chemotherapy cycles and/or allogeneic/autologous stem cells transplantation [29]. Treatment outcome depends on primary refractory disease to cure. Many patients experience a relapse. Additional tools that can detect the presence or absence of MRD after induction of remission may help to identify patients at risk of relapse. Clearly the use of MRD measurement to guide intensification of therapy is helpful only when there are adjunctive treatment options that could be added for patients who are MRD-positive during periods of hematologic remission [30].

MFC techniques are based on normal differentiation patterns of expression antigens that characterize the diverse lineages of normal hematopoietic cells. AML blasts present distinct immunophenotype patterns that are not detectable on the surface of bone marrow cells from healthy donors [31]. The aberrant patterns of antigen expression in leukemic patients, LAIP in AML have shown to be heterogeneous and thus several LAIP have been observed within an AML patient. When this occurs, the LAIP with the major logarithmic difference relative to normal bone marrow is used to monitor MRD. During MRD monitoring the residual levels of leukemic cells are evaluated by determining the log difference between the percent LAIP at diagnosis and at follow up [32]. MFC approaches can include three-to ten-color antibody panels with the ability to detect population between $0.1 \%$ and $0.01 \%$ of bone marrow nucleated cells. However, as the number of parameters evaluated by MFC in single tube increases, the complexity of analysis 
increases too. In addition to LAIP, stem cells immunophenotype has been also tested for its utility at detecting MRD. Patients presenting higher proportion of stem cells (defined as CD34+CD38-) demonstrate significantly lower relapse-free survival than patients with fewer stem cells [33].

Several studies in children as well as adults have shown that MRD detection by MFC provides strong prognostic information in AML after both induction and consolidation [34, 35, 36]. Importantly, one has to realize that most of these studies were retrospective in a single institute setting, thus introducing well known potential bias. By identifying cut-off values in the order of $0.01 \%-0.1 \%$ it has been possible in most of these studies to identify two patients groups with either poor or good prognosis. More recently, Van der Velden et al. [36] found that 3 -year relapse-free survival, after the first course of chemotherapy was $85 \%, 64 \%$, and $14 \%$ for patients with MRD less than $0.1 \%, 0.1 \%$ to less than $0.5 \%$ and $0.5 \%$ or higher, respectively. Among 188 patients with AML in remission after Induction 1, Loken et al. [37] found that 46 patients with positive MRD had a 3-year relapse-free survival of $30 \%$. A similar association was noted for MRD measured after Induction 2; MRD remained a significant prognostic factor in a multivariable model. Buccisano et al. [38] used MRD to stratify patients with good-risk and intermediate-risk cytogenetic. At the end of consolidation therapy, $68 \%$ good-risk and intermediate-risk patients were MRD-positive and had a relapse rate significantly higher than that of MRD-negative patients ( $74 \%$ versus $27 \%$ ). Thus, patients with MRD negativity at the end of consolidation had a relatively favorable outcome, whereas those with MRD positivity had an outcome similar to those with poor-risk molecular features. Rubnitz et al. [39] measured MRD after Induction 1 in 202 children with AML and detected levels of $0.1 \%$ or higher in $37 \%$ patients. A major difference between this study and all the others mentioned above was that MRD was used to adjust treatment intensity using reestablished cut-off levels. Inaba et al. [40] recently analyzed the results of MFC monitoring of MRD in samples obtained from 203 patients with newly diagnosed AML during and after completion of therapy. Of the 1,514 bone marrow samples studied, 202 (13.3\%) had $\mathrm{MRD} \geq 0.1 \%$ by MFC. A considerable number of samples with no morphologic evidence of disease contained leukemic cells, while some samples appearing to contain myeloblasts lacked detectable leukemic cells by MFC. Flow cytometric measurements of MRD after Induction 1 or 2 were strongly associated with event-free survival and higher relapse rate and were as an independent prognostic factor in multivariable analysis. Moreover, PCR testing did not identify patients with a worse outcome among those who were MRDnegative by MFC. The reason for the lack of relation between MRD estimated by MFC and PCR is unclear. It is possible that low levels of MRD by PCR (undetectable by MFC) may not be associated with relapse as low levels of disease might be suppressed by subsequent treatment [40].

These studies show that measurements of treatment response by MFC are widely applicable and provide strong prognostic information. A major criticism of MFC-based MRD assays is that results are highly operator-dependent and erroneous interpretation can occur if the interpreter has a less than extensive knowledge of normal hematopoietic immunophenotypic analysis. One suggestion by the international community has been development of software that allows for automated analysis of MFC data to provide accurate gating strategies. Currently, no consensus exists for standardized AML antibody panels or processing techniques, that makes reproducibility of methods difficult. Although in the past decade has been done dramatic progress in the understanding of AML biology, the improvements in patient outcomes have often failed to parallel these scientific advances [41].

\section{MRD and hematopoietic cell transplantation (HCT) in acute leukemia}

Allogeneic hematopoietic cell transplantation (HCT) is an established treatment for high-risk AML and ALL $[42,43]$. Recent studies have demonstrated high success rates for HCT in children regardless of matched donor availability. With contemporary HCT protocols, the mortality related to regimen toxicity, graft versus host disease (GVHD), and infection has decreased. However, HCT is not always curative and leukemia relapse occurs in a substantial number of patients [44]. Persistent MRD is a common indication for HCT in current protocols because it is associated with a high incidence of disease progression. For patients with either ALL or AML who achieve MRD-negativity, conversion to MRD positivity strongly suggests the possibility of relapse and should trigger careful monitoring. In AML, response to initial treatment dictates the intensity of subsequent therapy and identifies candidates for allogeneic HCT. Because of the increasing availability of MRD monitoring, the clinical usefulness of morphologic assessment of treatment response is now questionable. A further increase in MRD levels is usually followed by overt relapse $[2,3,45]$.

Levels of MRD before transplantation are strongly related to the post-transplantation relapse [46]. A study of Leung et al. [47] analyzing the significance of MRD pre-transplanted in 190 children with very high-risk ALL or AML found that survival probability was mostly dependent on MRD levels before transplantation regardless to whether patients were transplantated in first remission or with more advanced disease. In a subsequent analysis focusing on children with very high-risk ALL or AML, higher MRD levels at the time of transplantations predicted a poorer survival [48]. The increase in risk of death associated with any given level of MRD was greater in ALL than in AML, suggesting that a pretransplantation reduction of leukemia burden would have a higher impact in patients with ALL. MRD measurements can also be used to trigger retrieval post-transplantation efforts, e.g., tapering of immunosuppression, administration of donor lymphocyte infusions, and second hematopoietic 
cell transplantation. Because of its prognostic significance, MRD before transplantation is being increasingly applied to optimize the timing of transplantation and guide post-transplantation management [45]. In a study by Lankaster et al. [49] patients who were $M R D \geq 0.01 \%$ before transplantation were eligible for early tapering of cyclosporine post-transplantation treatment, resulting in an apparent delay in the occurrence of relapse. Not surprisingly, MRD is associated with other adverse risk factors, such as older age, poor-risk cytogenetics, leukemia arising from an antecedent hematologic disorder or after chemo-/radiotherapy and a multidrug resistance phenotype. The cumulative evidence convincingly demonstrates that MRD at the time of transplantation is a powerful, independent predictor of adverse outcome in patients with acute leukemia, and that monitoring MRD post-transplantation provides prognostic ally relevant information. On the other hand, it is currently unclear how the MRD status at the time of transplantation and at subsequent times post-transplantation should guide therapeutic decisions. We now have that capability, and the availability of reliable MRD measures pre- and post-transplantation provides the clinical transplant community with a great opportunity that should be exploited. Some studies hint at immunotherapy (for example, rapid withdrawal of immune suppression and/or donor lymphocyte infusions) as means to prevent overt relapse if patients remain, or become, MRD+ after HCT. Ultimately, controlled clinical studies are needed to define the value of MRD-directed therapies, and patients should be encouraged to enter such trials [50].

\section{Conclusions and considerations for the future}

The introduction of MRD monitoring has transformed the way in which patients with acute leukemia are managed. MRD results can be applied to most patients with ALL and AML, and can be delivered in a timely fashion to satisfy the requirements for rapid changes in treatment timing and intensity [51]. A further increase in cure rates for patients with acute leukemia will require accurate prediction of their relapse hazard. MRD assays now allow the objective and sensitive assessment of treatment response in virtually all patients. Despite this progress there are areas for continuing development. Methods to study MRD by MFC are constantly being refined by the introduction of new markers [18], which take advantage of the capacity of newer instruments to detect an increasingly higher number of fluorochromes. The recent technical innovations in routine FCM ( 3 lasers and $\geq 8$ colors) and the new developments in software for data analysis make this technology the most attractive for MRD diagnostics. Efforts to generate programs that can take full advantage of newer technologies and markers are being reported [52]. Immunophenotyping by mass cytometry, a new technology, provides the ability to measure $>36$ proteins at a rate of 1000 cells/second. Both MFC and mass cytometry have unique and powerful features as well as unique challenges and limitations. Over the next decade, these complementary technologies will play central roles in dissecting the complex interactions of cells [53]. An alternative approach to immunophenotypic analysis of MRD, based on high-speed cell imaging scanning technology, was also recently proposed [54]. The data indicate that this method has the potential to identify MRD with a very high sensitivity and ensure that the signals detected originate from viable cells. Overall, the benefits of MFC for MRD measurement are: (a) its applicability to most patients with acute leukemia; (b) a relative rapid turnaround; (c) the technique allows single cell analysis; (d) it provides information on normal cell population as well; (e) it allows analysis of either live of fixed cells, thus it be combined with cell sorting if needed to study heterogeneous populations [30].

MRD has proven to be an independent prognostic factor in childhood and adult acute leukemia. MFC detection of aberrant immunophenotypes and PCR amplification of Ig/TCR genes are currently the most widely used techniques for MRD quantification each has specific advantages and disadvantages and can be applied to the most patients with acute leukemia. There highly quantitative, and as have been shown to this yield clinically informative results. The selection of one of these two methods depends on the existing expertise and facilities. It is now clear that MRD levels (at least during the early phases of treatment and before and post HCT) closely reflect the degree of persistent disease, and that the residual leukemic cell population revealed by MRD testing has the potential of causing acute leukemia recurrence $[16,40,50]$. Precise MRD levels and optimal sampling time-points have to be defined for each treatment protocol before MRD-based risk stratification can be implemented. Whether or not outcome of patients can be improved by integrating MRD into treatment decisions is currently the subject of several clinical trials [55]. The implementation of MRD studies in treatment protocols requires a strong interaction between MRD specialists and clinical oncologists.

Current goals should, thus, focus on integrating serial MRD assessment into cytogenetic and molecular results for optimized risk stratification and appropriately standardizing MRD technologies to allow reproducibility and multiinstitutional collaboration. MRD studies have revolutionized risk stratification in acute leukemia and have multiple applications in the management of patients. MRD is also beginning to be used to determine the efficacy of new anti-leukemia agents [56], and should be a valuable tool to accelerate the discovery of experimental agents with the highest antileukemic effect, thus adding new endpoints to more rapidly develop optimal treatment strategies.

Acknowledgments: We thank Dr. K. Polakova (Cancer Research Institute, Slovak Academy of Sciences, Bratislava, Slovakia) for critical reading of the manuscript. This work was supported by the Scientific Grant Agency of the Ministry of Education of Slovak Republic and the Academy of Sciences (VEGA) under the contract No 2/0134/13. 


\section{References}

[1] BRUGGEMANN M, RAFF T, KNEBA M Has MRD monitoring superseded other prognostic factors in adult ALL? Blood 2012; 120: 4470-4481. http://dx.doi.org/10.1182/blood-2012$\underline{\text { 06-379040 }}$

[2] CAMPANA D Minimal residual disease in acute lymphoblastic leukemia. Hematol Am Soc Hematol Educ Program 2010; 2010: 7-12.

[3] CAMPANA D Minimal residual disease monitoring in childhood acute lymphoblastic leukemia. Curr Opin Hematol 2012; 19: 313-318. http://dx.doi.org/10.1097/ MOH.0b013e3283543d5c

[4] BARTRAM CR, SCHRAUDER A, KOHLER R, SCHRAPPE M Acute lymphoblastic leukemia in children. Dtsch Arztebl Int 2012; 109: 652-658.

[5] FRONKOVA E, MUZIKOVA K, MEJSTRIKOVA E, KOVAC $\mathrm{M}$, FORMANKOVA $\mathrm{R}$ et al. B-cell reconstitution after allogeneic SCT impairs minimal residual disease monitoring in children with ALL. Bone Marrow Transplant 2008; 42: 187-196. http://dx.doi.org/10.1038/bmt.2008.122

[6] CAZZANIGA G, VALSECCHI MG, GAIPA G, CONTER $\mathrm{V}, \mathrm{BIONDI} A$ Defining the correct role of minimal residual disease tests in the management of acute lymphoblastic leukaemia. Brit J Haematol 2011; 155: 45-52. http://dx.doi. org/10.1111/j.1365-2141.2011.08795.x

[7] BRUGGEMANN M, SCHRAUDER A, RAFF T, PFEIFER $\mathrm{H}, \mathrm{DWORZAK} \mathrm{M}$ et al. Standardized MRD quantification in European ALL trials: Proceedings of the Second International Symposium on MRD assessment in Kiel, Germany, 18-20 September 2008. Leukemia 2010; 24: 521-535. http://dx.doi. org/10.1038/leu.2009.268

[8] KALINA T, FLORES-MONTERO J, VAN DER VELDEN VHU, MARTIN-AYUSO M, BOTTCHER S et al. EuroFlow standardization of flow cytometer instrument settings and immunophenotyping protocols. Leukemia 2012; 26: 1986-2010. http://dx.doi.org/10.1038/leu.2012.122

[9] DWORZAK MN, SCHUMICH A, PRINTZ D, POTSCHGER U, HUSAK Z et al. CD20 up-regulation in pediatric $B$-cell precursor ALL during induction treatment: setting the stage for anti-CD20 directed immunotherapy. Blood 2008; 112: 3982-3988. http://dx.doi.org/10.1182/blood-2008-06$\underline{164129}$

[10] BJORKLUND E, MATINLAURI I, TIERENS A, AXELSSON $S$, FORESTIER E et al. Quality control for flow cytometry data analysis for evaluation of minimal residual disease in bone marrow from acute leukemia patients during treatment. J Pediatr Hematol Oncol 2009; 31: 406-415. http://dx.doi. org/10.1097/MPH.0b013e3181a1c0e8

[11] DENYS B, VAN DER SLUIJS-GELLING AJ, HOMBURG C, VAN DER SCHOOT CE, DE HAAS V et al. Improved flow cytometric detection of minimal residual disease in childhood acute lymphoblastic leukemia. Leukemia 2013; 27: 635-641. http://dx.doi.org/10.1038/leu.2012.231

[12] RYAN J, QUINN F, MEUNIER A, BOUBLIKOVA L, CRAMPE $\mathrm{M}$ et al. Minimal residual disease detection in childhood acute lymphoblastic leukemia patients at multiple time-points reveals high levels of concordance between molecular and immunophenotypic approaches. Br J Haematol 2009; 144: 107-115. http://dx.doi.org/10.1111/j.1365-2141.2008.07429. $\underline{\mathrm{x}}$

[13] GAIPA G, CAZZANIGA G, VALSECCHI MG, PANZERGRUMAYER R, BULDINI B et al. Time point-dependent concordance of flow cytometry and RQ-PCR in minimal residual disease detection in childhood acute lymphoblastic leukemia. Haematologica 2012; 97: 1582-1593. http://dx.doi. org/10.3324/haematol.2011.060426

[14] THORN I, FORESTIER E, BOTLING J, THURESSON B, WASSLAVIK C et al. Minimal residual disease assessment in childhood acute lymphoblastic leukemia: a Swedish multicentre study comparing real-time polymerase chain reaction and multicolor flow cytometry. Br J Haematol 2011; 152: 743-753. http://dx.doi.org/10.1111/j.1365-2141.2010.08456. $\underline{\mathrm{x}}$

[15] VAN DONGEN JJ, LHEMITTE L, BOTTCHER S, ALMEIDA J, VAN DER VELDEN VH et al. EuroFlow antibody panels for standardized n-dimensional flow cytometric immunophenotyping of normal, reactive and malignant leukocytes. Leukemia 2012; 26: 1908-1975. http://dx.doi.org/10.1038/ $\underline{\text { leu. } 2012.120}$

[16] COUSTAN-SMITH E, CAMPANA D Immunologic minimal residual detection in acute lymphoblastic leukemia: a comparative approach to molecular testing. Best Pract Res Clin Haematol 2010; 23: 347-358. http://dx.doi.org/10.1016/ j.beha.2010.07.007

[17] CAMPANA D Should minimal residual disease monitoring in acute lymphoblastic leukemia be standard of care? Curr Hematol Malig Rep 2012; 7: 170-177. http://dx.doi. org/10.1007/s11899-012-0115-4

[18] COUSTAN-SMITH E, SONG G, CLARK C, KEY L, LIU P et al. New markers for minimal residual disease detection in acute lymphoblastic leukemia. Blood 2011; 117: 6267-6276. http://dx.doi.org/10.1182/blood-2010-12-324004

[19] BOROWITZ MJ, DEVIDAS M, HUNGER SP, BOWMAN WP, CARROL AL et al. Clinical significance of minimal residual disease in childhood acute lymphoblastic leukemia and its relationship to other prognostic factors. A Children's Oncology Group study. Blood 2008; 111: 5477-5485. http://dx.doi. org/10.1182/blood-2008-01-132837

[20] BASSO G, VELTRONI M, VALSECCHI MG, DWORZAK $\mathrm{MN}$, RATEI $\mathrm{R}$ et al. Risk of relapse of childhood acute lymphoblastic leukemia is predicted by flow cytometric measurement of residual disease on day 15 bone marrow. J Clin Oncol 2009; 27: 5168-5174. http://dx.doi.org/10.1200/ LCO.2008.20.8934

[21] CONTER V, BARTRAM CR, VALSECCHI MG, SCHRAUDER A, PANZER-GRUMAYER R et al. Molecular response to treatment redefines all prognostic factors in children and adolescents with B-cell precursor acute lymphoblastic leukemia: results in 3148 patients of the AIEOP-BFM ALL 2000 study. Blood 2010; 115: 3206-3214. http://dx.doi.org/10.1182/blood2009-10-248146

[22] STOW P, KEY L, CHEN X, PAN Q, NEALE GA et al. Clinical significance of low levels of minimal residual disease at 
the end of remission induction therapy in childhood acute lymphoblastic leukemia. Blood 2010; 117: 6267-6276.

[23] VAN DER VELDEN V, CORRAL L, VALSECCHI MG, JANSEN MW, DE LORENZO P et al. Prognostic significance of minimal residual disease in infants with acute lymphoblastic leukemia treated within the Interfant-99 protocol. Leukemia 2009; 23: 1073-1079. http://dx.doi.org/10.1038/ leu.2009.17

[24] SCHRAPPE M, VALSECCHI MG, BARTRAM CR, SCHRAUDER A, PANZER-GRUMAYER R et al. Late minimal residual disease response determines relapse risk overall and in subsets of childhood T-cell ALL: results of the AIEOP-BFMALL 2000 study. Blood 2011; 118: 2077-2084. http://dx.doi. org/10.1182/blood-2011-03-338707

[25] BRUGGEMANN M, RAFF T, FLOHR T, GOKBUGET N, NAKAO $\mathrm{M}$ et al. Clinical significant of minimal residual disease quantification in adult patients with standard-risk acute lymphoblastic leukemia. Blood 2006; 107: 1116-1123. http://dx.doi.org/10.1182/blood-2005-07-2708

[26] BASSAN R, SPINELLI O, OLDANI E, INTERMESOLI T, TOSI $\mathrm{M}$ et al. Improved risk classification for risk-specific therapy based on the molecular study of minimal residual disease in adult ALL. Blood 2009; 113: 4153-4162. http://dx.doi. org/10.1182/blood-2008-11-185132

[27] PATEL B, RAI L, BUCK G, RICHARDS SM, MORTUZA Y et al. Minimal residual disease is a significant predictor of treatment failure in non-T lineage adult acute lymphoblastic leukaemia: final results of the international trial UKALL XII/ECOG2993. Br J Hematol 2010; 148: 80-89. http://dx.doi. org/10.1111/j.1365-2141.2009.07941.x

[28] GARAND R, BELDJORD K, CAVE H, FOSSAT C, ARNOUX I et al. Flow cytometry and IG/TCR quantitative PCR for minimal residual disease in acute lymphoblastic leukemia: a French multicenter prospective study on behalf of the FRALLE, EORTC and GRAALL. Leukemia 2013; 27:370-376. http://dx.doi.org/10.1038/leu.2012.234

[29] ROBOZ GJ Current treatment of acute myeloid leukemia. Curr Opin Oncol 2012; 24: 711-719. http://dx.doi.org/10.1097/ CCO.0b013e328358f62d

[30] CARLSON K-S B, GUZMAN ML Is minimal residual disease monitoring clinically relevant in adults with acute myelogenous leukemia? Curr Hematol Malig Rep 2013; 8: 109-115. http://dx.doi.org/10.1007/s11899-013-0157-2

[31] OSSENKOPPELE GJ, VAN DE LOOSDRECHT AA, SCHUURHUIS GJ Review of the relevance of aberrant antigen expression by flow cytometry in myeloid neoplasms. Br J Haematol 2011; 153: 421-436. http://dx.doi.org/10.1111/ j.1365-2141.2011.08595.X

[32] BUCCISANO F, MAURILLO L, SPAGNOLI A, DEL PRINCIPE MI, CERESOLI E Monitoring of minimal residual disease in acute myeloid leukemia. Curr Opin Oncol 2009; 21: 582588. http://dx.doi.org/10.1097/CCO.0b013e3283311856

[33] VAN RHENEN A, MOSHAVER B, KELDER A, FELLER N, NIEUWINT AW et al. Aberrant marker expression patterns on the CD34+CD38- stem cells compartment in acute myeloid leukemia allows to distinguishing the malignant from the normal stem cell compartment both at diagnosis and in remission. Leukemia 2007; 21: 1700-1707. http://dx.doi. org/10.1038/sj.leu.2404754

[34] MAURILLO L, BUCCISANO F, DEL PRINCIPE MI, DEL POETA G, SPAGNOLI A et al. Toward optimization of post remission therapy for residual disease-positive patients with acute myeloid leukemia. J Clin Oncol 2008; 26: 4944-4951. http://dx.doi.org/10.1200/JCO.2007.15.9814

[35] AL-MAWALI A, GILLIS D, LEWIS I The use of receiver operating characteristic analysis for detection of minimal residual disease using five-color multiparameter flow cytometry in acute myeloid leukemia identifies patients with high risk of relapse. Cytometry B 2009; 76: 91-101.

[36] VAN DER VELDEN VH, VAN DER SLUIJS-GELING A, GIBSON BE, TE MARVELDE JG, HOOGEVEEN PG et al. Clinical significance of flow cytometric minimal residual disease detection in pediatric acute myeloid leukemia patients treated according to the DCOG ANLL97/MRC AML12 protocol. Leukemia 2010; 24: 1599-1606. http://dx.doi. org/10.1038/leu.2010.153

[37] LOKEN MR, ALONZO TA, PARDO L, GERBING RB, RAIMOND SC et al. Residual disease detected by multidimensional flow cytometry signifies high relapse risk in patients with de novo acute myeloid leukemia: a report from Children's Oncology Group. Blood 2012; 120: 1581-1588. http://dx.doi.org/10.1182/blood-2012-02-408336

[38] BUCCISANO F, MAURILLO L, SPAGNOLI A, DEL PRINCIPE MI, FRABONI D et al. Cytogenetic and molecular diagnostic characterization combined to post consolidation minimal residual disease assessment by flow cytometry improves risk stratification in adult acute myeloid leukemia. Blood 2010; 116: 2295-2303. http://dx.doi.org/10.1182/blood$\underline{2009-12-258178}$

[39] RUBNITZ JE, INABA H, DAHL G, RIBEIRO RC, BOWMAN WP et al. Minimal residual disease-directed therapy for childhood acute myeloid leukaemia: results of the AML02 multicentre trial. Lancet Oncol 2010; 11: 543-552. http:// dx.doi.org/10.1016/S1470-2045(10)70090-5

[40] INABA H, COUSTAN-SMITH E, CAO X, POUNDS SB, SHURTLEFT SA et al. Comparative analysis of different approaches to measure treatment response in acute myeloid leukemia. J Clin Oncol 2012; 30: 3625-3632. http://dx.doi. org/10.1200//CO.2011.41.5323

[41] DINARDO CD, LUGER SM Beyond morphology: minimal residual disease detection in acute myeloid leukemia. Curr Opin Hematol 2012; 19: 82-88.

[42] FANG M, STORER B, WOOD B, GYURKOCZA B, SANDMAIER BM et al. Prognostic impact of discordant results from cytogenetics and flow cytometry in patients with acute myeloid leukemia undergoing hematopoietic cell transplantation. Cancer 2012; 118: 2411-2419. http://dx.doi. org/10.1002/cncr.26539

[43] DONEY K, GOOLEY TA, DEEG HJ, FLOWERS ME, STORB $\mathrm{R}$ et al. Allogeneic hematopoietic cell transplantation with fullintensity conditioning for adult acute lymphoblastic leukemia: results from a single center, 1998-2006. Biol Blood Marrow Transplant 2011; 17: 1187-1195. http://dx.doi.org/10.1016/ j.bbmt.2010.12.699 
[44] WAYNE AS, BAIRD K, EGELER RM Hematopoietic stem cell transplantation for leukemia. Pediatr Clin North Am 2010; 57: 1-25. http://dx.doi.org/10.1016/j.pcl.2009.11.005

[45] CAMPANA D, COUSTAN-SMITH E Measurement of treatment response in childhood acute leukemia. Korean J Hematol 2012; 47: 245-254. http://dx.doi.org/ 10.5045/kjh.2012.47.4.245

[46] BADER P, KREYENBERG H, HENZE GH, ECKERT C, REISING $\mathrm{M}$ et al. Prognostic value of minimal residual disease quantification before allogeneic stem cell transplantation in relapsed childhood acute lymphoblastic leukemia: the ALLREZ BFM Study Group. J Clin Oncol 2009; 27: 377-384. http://dx.doi.org/10.1200/JCO.2008.17.6065

[47] LEUNG W, CAMPANA D, YANG J, PEI D, COUSTANSMITH E et al. High success rate of hematopoietic cell transplantation regardless of donor source in children with very high-risk leukemia. Blood 2011; 118: 223-230. http:// dx.doi.org/10.1182/blood-2011-01-333070

[48] LEUNG W, PUI CH, COUSTAN-SMITH E, YANG J, PEI D et al. Detectable minimal residual disease before hematopoietic cell transplantation is prognostic but does not preclude cure for children with very high-risk leukemia. Blood 2012; 120: 468-472. http://dx.doi.org/10.1182/blood-2012-02-409813

[49] LANKESTER AC, BIERINGS MB, VAN WERING ER, WIJKHUIJS AJ, DE WEGER RA et al. Preemptive alloimmune intervention in high-risk pediatric acute lymphoblastic leukemia patients guided by minimal residual disease level before stem cell transplantation. Leukemia 2010; 24: 1462-1469. http://dx.doi.org/10.1038/leu.2010.133

[50] BUCKLEY SA, APPELBAUM FR, WALTER RB Prognostic and therapeutic implications of minimal residual disease at the time of transplantation in acute leukemia. Bone Marrow Transplant. 2013; 48: 630-641. http://dx.doi.org/10.1038/ bmt.2012.139

[51] PUI CH, CAMPANA D, PEI D, BOWMAN WP, SANDLUND JT et al. Treating childhood acute lymphoblastic leukemia without cranial irradiation. N Engl J Med 2009; 360: 27302741. http://dx.doi.org/10.1056/NEJMoa0900386

[52] FISER K, SIEGER T, SCHUMICH A, WOOD B, IRVING J et al. Detection and monitoring of normal and leukemic cell populations with hierarchical clustering of flow cytometry data. Cytometry A 2012; 81:25-34. http://dx.doi.org/10.1002/ cyto.a. 21148

[53] BENDALL SC, NOLAN GP, ROEDERER M, CHATTOPADHYAY PK A deep profiler's guide to cytometry. Trends in Immunol 2012; 33: 323-332. http://dx.doi.org/10.1016/ j.it.2012.02.010

[54] LIU X, HSIEH HB, CAMPANA D, BRUCE RH A new method for high speed, sensitive detection of minimal residual disease. Cytometry A 2012; 81: 169-175. http://dx.doi.org/10.1002/ cyto.a. 21124

[55] BRUGGEMANN M, GOKBUGET N, KNEBA M Acute lymphoblastic leukemia: Monitoring minimal residual disease as a therapeutic principle. Semin Oncol 2012; 39: 47-57. http://dx.doi.org/10.1053/j.seminoncol.2011.11.009

[56] TOPP MS, KUFER F, GOKBUGET N, GOEBELER M, KLINGER $\mathrm{M}$ et al. Targeted therapy with the T-cell-engaging antibody blinatumomab of chemotherapy-refractory minimal residual disease in B-lineage acute lymphoblastic leukemia patients results in high response rate and prolonged leukemiafree survival. J Clin Oncol 2011; 29: 2493-2498. http://dx.doi. org/10.1200//CO.2010.32.7270 